\title{
Study of liver function tests in hypertensive disorders of pregnancy
}

\author{
Radhika Pusuloori' ${ }^{1}$, K. Dilzith Arora ${ }^{2 *}$ \\ ${ }^{1}$ Department of Obstetrics and Gynecology, Chalmeda Anandarao Institute of Medical Sciences, Karimnagar, \\ Telangana, India \\ ${ }^{2}$ Department of Community Medicine, Prathima Institute of Medical Sciences, Karimnagar, Telangana, India
}

Received: 27 December 2017

Accepted: 24 January 2018

\section{*Correspondence:}

Dr. K. Dilzith Arora,

E-mail: radhikaarora98@gmail.com

Copyright: (c) the author(s), publisher and licensee Medip Academy. This is an open-access article distributed under the terms of the Creative Commons Attribution Non-Commercial License, which permits unrestricted non-commercial use, distribution, and reproduction in any medium, provided the original work is properly cited.

\section{ABSTRACT}

Background: Hypertensive disorders of pregnancy with spectrum complications is one among leading causes of fetomaternal morbidity and mortality especially when its associated with HELLP syndrome.

Methods: The present prospective study was conducted over a period of three years in the department of obstetrics and gynecology at Chalmeda Anandarao Institute of Medical Sciences, Karimnagar, Telangana from January 2008 to January 2009. This is a prospective study on 50 pregnant women with $28-40$ weeks of gestation with diastolic BP $\geq 110 \mathrm{~mm} \mathrm{Hg}$ recorded 6 hours apart.

Results: This is a prospective study on 50 pregnant women with $28-40$ weeks of gestation with diastolic $\mathrm{BP} \geq 110 \mathrm{~mm}$ $\mathrm{Hg}$ recorded 6 hours apart. Severe pre eclampsia was seen in younger age group $<25$ years. In patients with raised LFTs unbooked cases were more $(64 \%)$ showing complications are more in unbooked cases. Renal complications are seen in $16 \%$ of the total cases and in $28 \%$ of the cases with raised LFTs. In overall study group number of primi gravid were $50 \%$ and multi were $27 \%$. Incidence of severe pre eclampsia was $78 \%$ in overall cases. In patients with raised LFTs the incidence was $30(88 \%)$.

Conclusions: Detection of increased LFTs in cases of severe pre-eclampsia is a risk category, associated with increased rate of feto-maternal complications, compared to severe pre-eclampsia with normal LFTs. Such cases need special attention with early detection and referral to higher centre with better facilities of NICU set up to reduce the complications and mortality.

Keywords: LFTs, Hypertensive disorders, Pre eclampsia, Pregnancy

\section{INTRODUCTION}

Preeclampsia is a multisystem disorder, which occurs only in pregnant women during the second and third trimesters of pregnancy and is associated with raised blood pressure and proteinuria. It rarely presents before 20 weeks of gestation like in hydatidform mole. ${ }^{1}$ Eclampsia is a syndrome with one or more episodes of convulsions in association with preeclampsia. In normal pregnancy there is decreased blood pressure response to pressor substances but in preeclampsia there is marked response to vasopressin, norepinephrine and angiotensin.
This response of arterial system leads to generalized vasoconstriction and lhypertension in preeclampsia. Generalized vasoconstriction is responsible for decreased GFR and renal plasma flow. This causes alteration in various biochemical parameters. These alterations secondarily lead to many pathophysiological changes which adversely affect maternal and fetal wellbeing. The incidence of preeclampsia is commonly cited to be about $5 \%$ in the western countries. Incidence varies from $8-$ $10 \%$ in primigravida and $5 \%$ in multigravida. ${ }^{2}$ The hospital incidence in India ranges from 1 in 30 to 1 in 500. It is more common in primigravida (75\%), 5 times more 
in twin pregnancies and occurs between the 36 week and term in more than $50 \%$ cases. Faridmattar and BANA studied risk factors of maternal morbidity in eclampsia. Major maternal complications include abruption placenta (10\%) HELP syndrome (11\%) disseminated intravascular coagulopathy (6\%), aspiration pneumonitis $(7 \%)$, pulmonary edema $(5 \%)$ and death $(1 \%)$.

Several risk factors have been identified as predisposing to the development of preeclampsia in different populations. They include,

\section{Parity}

Hansen reported a two to three fold increase in the incidence in nulliparas and this was supported by Chesley. ${ }^{3}$ Sibai and his association recently reconfirmed the high risk of developing of pregnancy induced hypertension in primis.

\section{Age}

Spelacy et al evaluated that women of either end of reproductive age group are more susceptible to preeclampsia. Maternal age <20years old was the strongest risk factor for both preeclampsia and eclampsia. ${ }^{4}$

\section{Family history}

Family aspect of pregnancy was studied by Adams fin Layson. ${ }^{5}$ Any differences in preeclampsia incidence seen in the racial groups may in fact be explained by differences in maternal height, weight (both underweight and overweight) age and possible differences in social class. Hamilton observed that twin gestation predisposes to eclampsia. He concluded that risk increases six times in preeclampsia. Incidence of preeclampsia and eclampsia is great in twin pregnancy with a prevalence of up to 29\%. Pricilla White described that diabetes mellitus predisposed to eclampsia. ${ }^{6}$ Seitz recognized that preeclampsia is sometimes superimposed upon chronic hypertension.

\section{Hydatiform mole}

It substantially increases the risk of preeclampsia associated with abnormalities of glomerular histology. Hydropsfetalis, triploidy, fetal malformations and polyhydramnios are some conditions, which predispose to preeclampsia. $^{7}$ Others include obesity, socio-economic status, oral contraception usage and cigarette smoking also play a role in the disease.

\section{Medical conditions}

Chronic renal disease Antiphospholipid antibody syndrome, Connective tissue diseases Thrombophilia. Liver function abnormalities and renal function abnormalities are the important effects. ${ }^{8}$ Preeclampsia is associated with substantial risks for the fetus, which include intrauterine growth retardation, death and prematurity with associated complications. Whereas mother is at risk of seizures (eclampsia), renal failure, pulmonary edema, stroke and death. Even after considerable research, the cause for preeclampsia remains unclear and there are no useful screening tests in early diagnosis of preeclampsia. $^{9}$ In HELLP syndrome, an elevation in liver function test results is noted. ${ }^{10}$ Periportal hemorrhagic necrosis in the periphery of the liver lobule is Liver Function Test (LFT) abnormalities occur in $3 \%$ of the pregnancies, and probably the lesion that causes elevated serum liver enzymes. ${ }^{11}$

With severe renal involvement, glomerular filtration may be impaired, and the plasma creatinine concentration may begin to rise. Elevated uric acid is another component of the preeclampsia. Although hyperuricemia does correlate with maternal morbidity, there is an even stronger association of uric acid with the risk for small birth weight infants and with overall fetal mortality. ${ }^{12}$ The hyperuricemia of preeclampsia has been variably suggested to be associated with lactic acidosis, altered renal functions or oxidative stress. ${ }^{13}$ The aim of the study was to compare liver function tests and renal function tests in preeclampsia and eclampsia with normal pregnancy.

\section{METHODS}

This is a prospective study on 50 pregnant women with 28-40 weeks of gestation with diastolic $\mathrm{BP} \geq 110 \mathrm{~mm} \mathrm{Hg}$ recorded 6 hours apart.

\section{Inclusion criteria}

- Pregnant women with 28-40 weeks of gestation.

- Diastolic BP $\geq 110 \mathrm{~mm} \mathrm{Hg}$ admitted into the hospital.

- Patient with headache, visual symptoms, oliguria, upper abdominal pain and other symptoms of severe PIH (pregnancy induced hypertension).

\section{Exclusion criteria}

- All patients with present or recent past history of liver diseases like jaundice, viral hepatitis, hepatobiliary, alcoholic liver diseases etc.

- All patients taking hepatotoxic drugs like anti tuberculous drugs, anti convulsant drugs.

\section{Blood pressure recording}

Measured in right arm both in sitting of left lateral lying position at the level of heart preferably two times with 6 hours of bed rest.

Cut off point for diastole was korotk phase V sound using appropriate cuff depending on patients arm girth.

Diastole $\geq 110 \mathrm{~mm} \mathrm{Hg}$ were selected for the study. 


\section{History an examination}

Detailed history of the patient taken from the patients and her relatives. Complete general and systemic examination and obstetric examination done.

\section{Investigations}

Complete haemogram: $\mathrm{Hb} \%$, blood grouping and $\mathrm{Rh}$ typing, screeing test, HBs Ag, platelet count, random blood sugar.

\section{LFTS}

- AST/ALT/ALP

- Total and direct bilirubin

- AG ratio,

- $\mathrm{LDH}$

\section{Renal}

Blood urea, serum creatinine, serum uric acid.

LFTs and renal parameters to be repeated alternate days if the diastolic $\mathrm{BP} \geq 100 \mathrm{~mm} \mathrm{Hg}$. If the diastolic $\mathrm{BP}<100 \mathrm{~mm}$ $\mathrm{Hg}$, biochemical profile to be repeated twice a week. Anyone parameter abnormal in LFT was considered as abnormal LFT. Urine is tested for albumin by dipstic method daily. Bleeding time and clotting time, done bed time.

\section{Complete HELLP Syndrome}

All the three of the following are abnormal

- Tests foe hemolysis

- Liver enzymes

- Platelet count

\section{Partial HELLP Syndrome}

Any one or two of the above are abnormal

\section{Treatment and follow up:}

Patients are treated with Tab. Alpha Methyldopa250 mg TID and tab. Nifedipine $10 \mathrm{mg}$ BD increased depending on diastolic blood pressure. Magnesium sulphate started prophylactically using Pritchard regimen, continued 24 hours of post delivery or convulsion whichever later.

Blood and blood products transfused according to necessity terminating the pregnancy either vaginal by cesarean section done depending on gestational age, presentation and position of the fetus, the severity and control of BP, fetal condition, complications in the mother. Patients were followed until discharge and LFTs were done 2 weeks after delivery.

\section{RESULTS}

Most of the patients were in the age group of 21-25 years. Severe pre eclampsia was seen in younger age group ( $<25$ years). $50 \%$ among the patients with raised LFTs are between 21-25 years. Mean age group is 22.5. In Normal group $<20$ years LFTs were in $9(22 \%$ of patients), 21-25 years LFTs were $11(22 \%), 26-30$ years LFTs were 4 (8\%), 31-35 years LFTs were 1 (2\%).

Table 1: Comparison of LFTs in different age groups.

\begin{tabular}{|c|c|c|}
\hline \multirow{2}{*}{ Age } & \multicolumn{2}{|l|}{ LFTs } \\
\hline & Normal & Raised \\
\hline$<20$ Years & 9 & 7 \\
\hline 21-25 Years & 11 & 13 \\
\hline 26-30 Years & 4 & 4 \\
\hline 31-35 Years & 1 & 1 \\
\hline
\end{tabular}

In raised group $<20$ years LFTs were in 7 (14\%) of patients), 21-25 years LFTs were 13 (26\%), 26-30 years LFTs were 4 (8\%), 31-35 years LFTs were $1(2 \%)$.

Table 2: Booking status and LFTs in severe preeclampsia (SPE).

\begin{tabular}{|c|c|c|}
\hline \multirow{2}{*}{ Status } & \multicolumn{2}{|l|}{ LFTs } \\
\hline & Normal & Raised \\
\hline $\mathrm{BC}$ & 16 & 9 \\
\hline UB & 9 & 16 \\
\hline
\end{tabular}

In overall study group booked and unbooked status were equal. In patients with raised LFTs unbooked cases were more $(64 \%)$ showing complications are more in unbooked cases. Statistical significant relation is seen between raised LFT and unbooked cases.

Table 3: Renal function tests and LFTs.

\begin{tabular}{|c|c|c|}
\hline \multirow{2}{*}{ Status } & \multicolumn{2}{|l|}{ LFTs } \\
\hline & Normal & Raised \\
\hline Normal & 24 & 18 \\
\hline Raised & 1 & 7 \\
\hline
\end{tabular}

Renal complications were seen in $16 \%$ of the total cases and in $28 \%$ of the cases with raised LFTs. In normal group LFTs were normal in 24 (48\% of patients), in raised group LFTs were normal in 1 ( $2 \%$ of patients), in raised group LFTs were normal in 18 (36\% of patients), in raised group LFTs were normal in 7 ( $14 \%$ of patients).

Table 4: Parity and LFTs.

\begin{tabular}{|lll|} 
Status & LFT's & \\
& Normal & Raised \\
\hline Primi & 6 & 22 \\
\hline Multi & 14 & 8 \\
\hline
\end{tabular}

$\mathrm{X}^{2}-9.12, \mathrm{P}-<0.01$, Highly significant 
In overall study group number of primi gravid were $50 \%$ and multi were $44 \%$. In raised LFTs group primi gravid were $73 \%$ and multi were $27 \%$.

Table 5: Eclampsia and LFTs in severe pre eclampsia.

\begin{tabular}{|lll|}
\hline Status & LF'Ts & \\
\hline SPE & Normal & Raised \\
\hline E & 9 & 30 \\
\hline$X^{2}-6.48, P-<0.05$, & 7 & 4 \\
\hline
\end{tabular}

$\mathrm{X}^{2}-6.48, \mathrm{P}-<0.05$, significant.

Statistically significant relation is seen between raised LFT and number of patients with severe pre eclampsia. Incidence of SPE was $78 \%$ in over all cases. In patients with raised LFTs the incidence was $30(88 \%)$. In normal group SPE were seen in 9 cases, Eclampsia were seen in 7 cases only. In raised group SPE were seen in 30 cases, Eclampsia were seen in 4 cases only.

Table 6: Systolic blood pressure and LFTs.

\begin{tabular}{|lll|}
\hline SBP & LFT's & \\
\hline$<160$ & Normal & Raised \\
\hline 160 & 6 & 22 \\
\hline
\end{tabular}

In the total study group, $60 \%$ had raised LFTs with systolic blood pressures more than or less than $160 \mathrm{~mm}$ hg. In the group with systolic pressure more than $160 \mathrm{~mm}$ $\mathrm{Hg}, 78 \%$ had raised LFTs.

Table 7: Platelet count and LFT.

\begin{tabular}{|lll|}
\hline Platelet & LFTs & \\
\hline Normal & 10 & Increased \\
\hline Decreased & 2 & 31 \\
\hline
\end{tabular}

$\mathrm{X}^{2}-0.0168, \mathrm{P}-<0.05$, Highly significant.

Total number of cases with decreased platelet count 9 (18\%). Among the group of raised LFTs, 7 cases had decreased platelet count. Statistical study should that the decrease in platelet has no significant correlation with raised LFT.

Table 8: Treatment.

\begin{tabular}{|lll|}
\hline Treatment & LFTs & \\
\hline Nifedipine & 2 & 1 \\
\hline Methyl dopa & 4 & 0 \\
\hline Methyl dopa+Nifedipine & 6 & 2 \\
\hline Methyl dopa+MgSo 4 & 2 & 2 \\
\hline Methyl dopa+Nifedipine $+\mathrm{MgSo}_{4}$ & 11 & 20 \\
\hline
\end{tabular}

In total study $31(62 \%)$ needed all three drugs, $16 \%$ needed only one methyl dopa, $24 \%$ needed two drugs. Among the group with raised LFTs, $80 \%$ needed all the three drugs and needed more management.
Table 9: Mode of delivery.

\begin{tabular}{|lll|}
\hline Treatment & LFTs & \\
\hline Vag & Normal & Increased \\
\hline CS & 19 & 15 \\
\hline
\end{tabular}

Out of the total cases $68 \%$ delivered vaginally and $32 \%$ cases delivered by $\mathrm{C} / \mathrm{S}$. Among group of raised LFTs 60 $\%$ had vaginal delivery and $40 \%$ had $\mathrm{C} / \mathrm{S}$.

Table 10: Incidence of HELLP and partial HELLP.

\begin{tabular}{|lll|}
\hline Diagnosis & LFTs & \\
\hline HS & Normal & Raised \\
\hline PHS & - & 6 \\
\hline$X^{2}-7.13$, P-0.01, Signifi & 4 & 21 \\
\hline
\end{tabular}

$\mathrm{X}^{2}-7.13, \mathrm{P}-0.01$, Significant.

In the overall study the number of cases with HELLP syndrome were 6 (125) and partial HELLP 25 (50\%). Statistical studies showed significant correlation between incidence of HELLP and partial HELLP with raised LFTs.

\section{DISCUSSION}

Hypertensive disorders complicating pregnancies are common and form one of the deadly triad, along with hemorrhage and infection that contribute greatly to maternal morbidity and mortality. ${ }^{1}$

Berg and colleagues reported $16 \%$ of 3201 pregnancies related deaths in united states from 1991 to 1997.

Pre-eclampsia is a pregnancy specific syndrome of reduced organ perfusion secondary to vasospasm and endothelial cell activation. Proteinuria is an important sign of pre-eclampsia, but demonstration of significant proteinuria by clinically single randomized sample is variable because degree of proteinuria varies over 24hour period. ${ }^{2}$

Recent study of newman and co-workers 2003 shows worsening proteinuria resulted in increased preterm deliveries without proportionate increase in neonatal mortality.

Patients with diastolic BP greater than $110 \mathrm{~mm}$ of HG are categorized into severe pre-eclampsia like proteinuria $(+2)$, headache, epigastric pain, oliguria, raised liver function tests. ${ }^{3}$ In present study the incidence of HELLP syndrome is $12 \%$, partial HELLP 25 cases. Patients with altered liver function tests were $60 \%$, including both partial HELLP and HELLP syndrome.

Altered renal parameters seen in $8(26 \%)$ of total cases, and $5(20 \%)$ of cases raised liver function tests. It was most common complication seen in the study. Normal LFTs in 6\%. 
It is supported by a study of Cunningham of HELLP syndrome is also reported to be a major cause of renal in developing countries found renal compromise in $9.6 \%$ of their studies. Sibai et al reported $7.7 \%$ of acute renal failure in these cases. According to one study mild renal dysfunction is virtually universal. ${ }^{4,14}$

Incidence of postpartum hemorrhage was $6 \%$ of total cases and $8 \%$ of raised liver function test. Incidence of abruption was $10 \%$ of total cases $16 \%$ of cases of raised liver function tests.

The incidence of Nagoya of HELLP syndrome among women with pre-elampsia was $12.8 \%$ and the incidence among women with eclampsia was $19.8 \%$. HELLP syndrome was initially presented by preeclampsia (45.2\%) or eclampsia (46.2). In present study $14 \%$ of eclampsia seen in study group and in cases of raised liver function test $8 \%$ has eclampsia (significant $\mathrm{P}$ value). ${ }^{7}$,

\section{CONCLUSION}

Detection of increased LFTs in cases of severe preeclampsia is a risk category, associated with increased rate of feto-maternal complications, compared to severe pre-eclampsia with normal LFTs. Such cases need special attention with early detection and referral to higher centre with better facilities of NICU set up to reduce the complications and mortality.

\section{Funding: No funding sources}

Conflict of interest: None declared

Ethical approval: The study was approved by the Institutional Ethics Committee

\section{REFERENCES}

1. Aamoudse JG, Hollthoff. A syndrome of liver damage and intra vascular coagulation in the trimester of normotensive pregnancy. A clinical histopathological study. $\mathrm{Br} \mathrm{J}$ Obstet Gynecol. 1986;93:45-55.
2. Adlercreutz H, Tenhunen R. Some Spaects of interaction between natural and synthetic female sex hormones and the liver. Am J Med. 1970;49:620.

3. Aias F, Mancilla-Jimmenez R. hepatic fibrinogen deposits in pre-eclampsia. $\mathrm{N}$ Engl $\mathrm{J}$ Med. 1976;295:578.

4. Antia FP, Bharadwaj TP, Watsa MC, Master J. Liver in normal pregnancy, preeclampsia and eclampsia. Lancet. 1958 Oct 11;272(7050):776-8.

5. MacGillivray I. Hydramnios and preeclampsia Lancet. 1959:52-3.

6. Dutta DC. Text book of obstetrics; $4^{\text {th }}$ ed. Elsevier India;2013.

7. Arias F, Mancilla-Jimenez R. Hepatic fibrinogen deposits in pre-eclampsia. $\mathrm{N}$ Engl $\mathrm{J}$ Med. 1976;295:578.

8. Audibert F, Friedman SA, Frangieh AY, Sibai BM. Clinical utility of strict diagnosis criteria for the HELLP (hemolysis, elevated liver enzyme and low platelets) syndrome. Am J Obstet Gynecol. 1996;175:460-4.

9. Beller FK, Dame WR, Ebert C. pregnancy inducd hypertension complication by thrombocytopenia. Renal biopsies and outcome. Aust NZ J Obstet Gynecol. 1985;25:83.

10. Borglin NE, Serum transaminase activity in uncomplicated and complicated pregnancy and in new born. J clin endocrine metab, 1958; 18:872-7.

11. Broughton Pipkin F. Risk factors for pre eclampsia. N Engl J Med. 2001;344:925.

12. Carter I. Liver function in normal pregnancy. Aust NZ J Obstet Gynecol. 1990;30:296-302.

13. Calbereath DF. Clinical chemistry a fundamental text book. W.B. Saunders;1992:227-32.

14. Goodlin RC, Cotton DB, Haesslein HC. Severe oedema proteinuria-Hypertension gestosis. Am J Obstet Gynecol. 1978;132:595.

Cite this article as: Pusuloori R, Arora KD. Study of liver function tests in hypertensive disorders of pregnancy. Int J Reprod Contracept Obstet Gynecol 2018;7:1212-6. 